\title{
Services for stroke patients one year after stroke
}

\author{
JULIA LEGH-SMITH, DERICK T WADE, AND RICHARD LANGTON-HEWER \\ From the Stroke Unit, Frenchay Hospital, Bristol
}

SUMMARY The use of community services by stroke patients was investigated one year after their stroke. Survivors from a register of all patients from a defined community were followed up one year after their stroke. Four hundred and thirty six of the 492 survivors were seen: 301 lived at home with someone, 82 lived at home alone, and 53 were in long-stay care. One hundred and forty seven (38\%) of those at home were visited by one or more community services, the major ones being district nurse (73), home help (73), day rentres (42), and meals on wheels (30). Analysis suggests that these services reach the patients who need most help. However, some $57(19 \%)$ disabled patients are being looked after at home without any outside help.

Community services are essential in helping to maintain disabled stroke patients in their own homes. Without them many more patients would need to remain in hospital, nursing home or other long-stay accommodation. While the provision of services obviously depends on local and national policies, the personal and domestic care needs of patients are likely to be the same in any area. This study considers such needs and how they are met in the Frenchay Health District at one year after stroke. At this time functional ability is unlikely to improve, ${ }^{1}$ and services will probably be needed until the patient dies or has a further illness.

One British study ${ }^{2}$ described the use of community resources by patients surviving an acute stroke but only investigated 192 patients selected on the basis of hospital admission with a "moderately severe" stroke. It did not study 644 other patients discharged from hospital or any patients treated at home. In this selected group the more disabled patients received more services, but there was no information on those not receiving help.

Concern has been expressed ${ }^{34}$ that many demands are made of the carers of disabled elderly people at home. We have investigated the relationship between help available at home, physical and mental disability, and the use of community services in all survivors of an acute stroke coming from a defined population.

\section{Patients and methods}

This analysis is based on all surviving patients from a series ${ }^{5}$ of 976 acute strokes registered, over 28 months, in 215000 people cared for by 96 general practitioners (GPs) in the Frenchay Health District, Bristol. The district includes some isolated villages and farms, one town (Yate/Chipping Sodbury), and a wedge-shaped area of the city of Bristol encompassing suburban and urban housing. Notification of patients was accepted from anyone including GPs, district nurses, hospital staff, and even members of the public. Hospital wards were visited regularly to seek out patients, and the Regional Health Authority gave us the hospital numbers of all patients discharged with a primary or secondary diagnosis of stroke. All notifications were checked to ensure that the clinical diagnosis was acute stroke, ${ }^{6}$ that they were registered with the relevant GPs, and that their stroke had occurred between 1 March 1981 and 30 June 1983.

One year after the stroke every survivor was contacted for an interview; if possible, the chief carer living in the same house (usually the spouse or a close relative) was also interviewed. The type and frequency of services received were recorded for the preceding week (district nurse, home help, meals on wheels) or month (day centre, day hospital, volunteers, health visitor, domiciliary physiotherapy, laundry service, and GP). Visits by social workers were not included. Each patient was classified as living in independent accommodation either alone or with a carer (eg, spouse, child, friend), or living in long-stay accommodation (ie, hospital, nursing home, or elderly person's home with support from professional staff).

Functional disability was assessed using the Barthel Activities of Daily Living index. ${ }^{7}$ Scores of $0-14$ (out of 20) were taken to indicate "moderate or severe disability," 15-19 "mild disability," and 20 "independent" (not necessarily "normal") functioning. Selected items from this index have been analysed. Information on domestic activities was 
selected from the Frenchay activities index (FAI) ${ }^{8}$ (cooking, washing up, washing clothes, housework, and shopping). The middle two rating categories were combined to give three: never, occasional or frequent performance. Mental confusion was assessed using the Hodkinson's mental test, ${ }^{9}$ in which a score of $0-6$ indicates confusion and/or dementia, and 7-10 is "normal."

\section{Results}

A total of $492(50 \%)$ of the 976 patients registered with the Frenchay Stroke Project were still alive one year after their stroke. Fifty six patients $(11 \%)$ could not be seen: 11 had left the area, 20 could not be contacted, 17 were first registered after one year, and 8 refused to be seen. Of the 436 patients interviewed, $53(12 \%)$ were living in dependent accommodation and are treated as a separate group. Of the 383 living at home, $82(21 \%)$ lived alone and $301(79 \%)$ with one or more other persons. The spouse was the chief carer in $254(84 \%)$ instances (86 were husbands). Other carers were the patients' children, other relatives or friends. Spouses were significantly older than other carers: mean (SD) age $65.7(10.5)$ as compared with $53.0(16.3)(t=9 \cdot 22$ $\mathrm{p}<0.001)$.

One hundred and forty seven (38\%) patients living at home received one or more of the community services recorded (excluding seeing their GP). Table 1

Table 1 Services received by patients one year after stroke

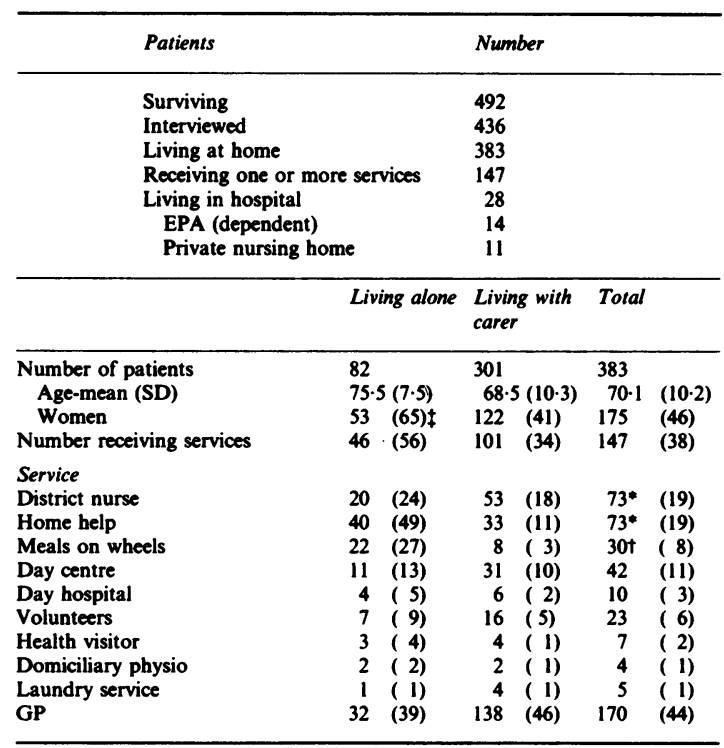

- $33(9 \%)$ patients received district nurse and home help

+ $12(3 \%)$ patients received district nurse, home help, and meals on wheels

$\mp$ Percentages in parentheses compares patients living alone with those living with carers, and their use of services. Patients living on theiro own were significantly older $(t=5.75 ; \mathrm{p}<0.001)$ and included more women (chi $=14.1 \mathrm{p}<0.001)$, and more received help $(\mathrm{chi}=12 \cdot 1 ; \mathrm{p}<0.001)$. Fewer than $10 \%$ of patients had help from volunteers, health visitors, domiciliary physiotherapists, or the laundry service. The frequency of contact with other services is shown in table 2. The commonest (modal) frequency of contact was every weekday for district nurses, 2-3 hours per week for home helps, and weekly attendance 0 at a day centre.

The use of the major services (district nurse, home $\frac{\overline{\bar{c}}}{\overline{5}}$ help, meals on wheels), a patient's disability, and the $\mathbb{D}$ presence of a carer are shown in table 3 . It can be seen that $60(20 \%)$ patients with moderate or severe disability were living with a carer and three were living. on their own. These latter three and the five mildly $\overrightarrow{\vec{H}}$ disabled patients living alone without services all had $\stackrel{\sigma}{\omega}$ help from relatives living nearby.

The relationships between these factors were $\stackrel{\bigcirc}{)}$ explored using chi-square or $t$ test analyses as $\overrightarrow{0}$ appropriate, at a significance level of $p<0.01$. Patien $\mathbb{R}_{\mathrm{N}}$ receiving help, whether living alone or with a care $\overrightarrow{ }, \vec{D}$ were likely to be more disabled and more confused $\rightarrow$ than those without help. Some patients could not assessed due to communication difficulties or distres, $\overrightarrow{ }$ but they, too, tended to need more help.

Patients living in dependent accommodation we significantly older and more disabled, had lowe $\overrightarrow{0}$ mental test scores, and were more likely to be wome than any of the four groups living at home. Nevertheless $63(62 \%)$ of the 103 patients with moderate or severe disability were living at home, most (60) with a carer. Only one patient without measurable physical disability lived in a nursing home $\frac{}{\varnothing}$ but showed signs of confusion such that she was considered "at risk" on her own.

Table 2 Receipt of services by 383 patients living at home

\begin{tabular}{|c|c|c|c|c|c|c|c|}
\hline \multirow[b]{2}{*}{ Service } & \multicolumn{2}{|l|}{ Received } & \multicolumn{5}{|c|}{ Frequency help given if received } \\
\hline & No & Yes & 1 & $2-3$ & $4-5$ & $6-7$ & 8 \\
\hline $\begin{array}{l}\text { District nurse } \\
\text { Home help } \\
\text { Meals on wheels } \\
\text { Day centre }\end{array}$ & $\begin{array}{l}310(81) \dagger \\
310(81) \\
353(92) \\
341(89)\end{array}$ & $\begin{array}{l}73 \\
73 \\
30 \\
42\end{array}$ & $\begin{array}{r}10 \\
2 \\
0 \\
3\end{array}$ & $\begin{array}{r}12 \\
40 \\
13 \\
2\end{array}$ & $\begin{array}{l}35 \\
27 \\
13 \\
28\end{array}$ & $\begin{array}{r}13 \\
4 \\
4 \\
2\end{array}$ & $\begin{array}{l}3 \\
0 \\
0 \\
7\end{array}$ \\
\hline Seen by GP & $213(56)$ & 170 & 142 & 21 & 7 & 0 & 0 \\
\hline
\end{tabular}

\footnotetext{
- Frequency categories are as follows:

District nurse $\quad$-. visits per week

Home help - hours per week

Meals on wheels - meals per week

Day centre - visits per month

Day hospital _ - visits per month

GP - visits during preceding month

$\uparrow$ Percentages in parentheses
} 
Some particular problems of those 73 patients receiving district nurse services compared with 236 having no services is shown in table 4. All patients living alone and needing help with feeding, dressing, bladder or mobility difficulties, or assessed as severely disabled received help. On the other hand, carers were presumably helping many $(12-24 \%)$ with personal care tasks. Only 3 of the 73 patients being seen by the district nurses did not need help in bathing, and this supports the impression that bathing was the major reason for many visits.

The association between handicap and receipt of services is further confirmed when domestic activities are considered. The total FAI scores were significantly lower in patients receiving services, whether living alone $(t=7.9 \mathrm{p}<0.001)$ or living with someone $(t=9.4$ $\mathrm{p}<0.001)$. Most of those living alone who did not cook, wash up, wash clothes, do housework or go shopping received help. Of those living with someone, many may have elected not to cook, etc, not because of any disability (table 5).

\section{Discussion}

Our results suggest that the National Health Service and local authority (social services) in the Frenchay

Table 3 One year assessments for patients receiving/not receiving services and living alone/with carer/long-stay care

\begin{tabular}{|c|c|c|c|c|c|}
\hline & \multicolumn{2}{|l|}{ Living alone } & \multicolumn{2}{|c|}{ Living with carer } & \multirow[t]{2}{*}{ Long-stay care } \\
\hline & Services & No services & Services & No services & \\
\hline $\begin{array}{l}\text { Number of patients } \\
\text { Age-Mean (SD) } \\
\text { Women }\end{array}$ & $\begin{array}{l}46 \\
77 \cdot 5(7 \cdot 0) \\
31 \quad(67)\end{array}$ & $\begin{array}{l}36 \\
73 \cdot 0(7 \cdot 5) \\
22 \quad(61)\end{array}$ & $\begin{array}{l}101 \\
71.9(9.4) \\
56(55)\end{array}$ & $\begin{array}{l}200 \\
66.9(10.3) \\
66(33)\end{array}$ & $\begin{array}{l}53 \\
78 \cdot 6(6 \cdot 2) \\
36 \quad(69)\end{array}$ \\
\hline $\begin{array}{l}\text { Disability } \\
\text { (Barthel Score) } \\
\text { Moderate/Severe (0-14) } \\
\text { Mild (15-19) } \\
\text { Normal (20) } \\
\text { Total: Mean (SD) }\end{array}$ & $\begin{array}{ll}3 & (7) \\
26 & (56) \\
17 & (37) \\
18 \cdot 2 & (2 \cdot 5)\end{array}$ & $\begin{array}{ll}0 & \\
5 & (14) \\
31 & (86) \\
19.9 & (0.3)\end{array}$ & $\begin{array}{cl}44 & (43) \\
50 & (50) \\
7 & (7) \\
14 \cdot 1 & (5 \cdot 1)\end{array}$ & $\begin{array}{c}16(8) \\
41 \quad(20) \\
143(72) \\
18 \cdot 7(3 \cdot 1)\end{array}$ & $\begin{array}{cl}41 & (77) \\
11 & (21) \\
1 & (2) \\
9.9 & (5 \cdot 4)\end{array}$ \\
\hline $\begin{array}{l}\text { Mental score } \\
\text { Unassessable } \\
\text { Confused (0-6) } \\
\text { Normal (7-10) } \\
\text { Total: Mean (SD) }\end{array}$ & $\begin{array}{cl}5 & (11) \\
9 & (19) \\
32 & (70) \\
8 \cdot 1 & (1 \cdot 7)\end{array}$ & $\begin{array}{c}1 \quad(3) \\
1 \quad(3) \\
34(94) \\
8.7(1.0)\end{array}$ & $\begin{array}{ll}10 & (10) \\
29 & (28) \\
62 & (62) \\
7 \cdot 1 & (2 \cdot 8)\end{array}$ & $\begin{array}{c}10(5) \\
17(8) \\
173(87) \\
8.7(1.8)\end{array}$ & $\begin{array}{l}19(36) \\
20(38) \\
14(26) \\
4.9(3.4)\end{array}$ \\
\hline
\end{tabular}

Percentages in parentheses

Table 4 Selected Barthel items for patients receiving/not receiving district nurse services

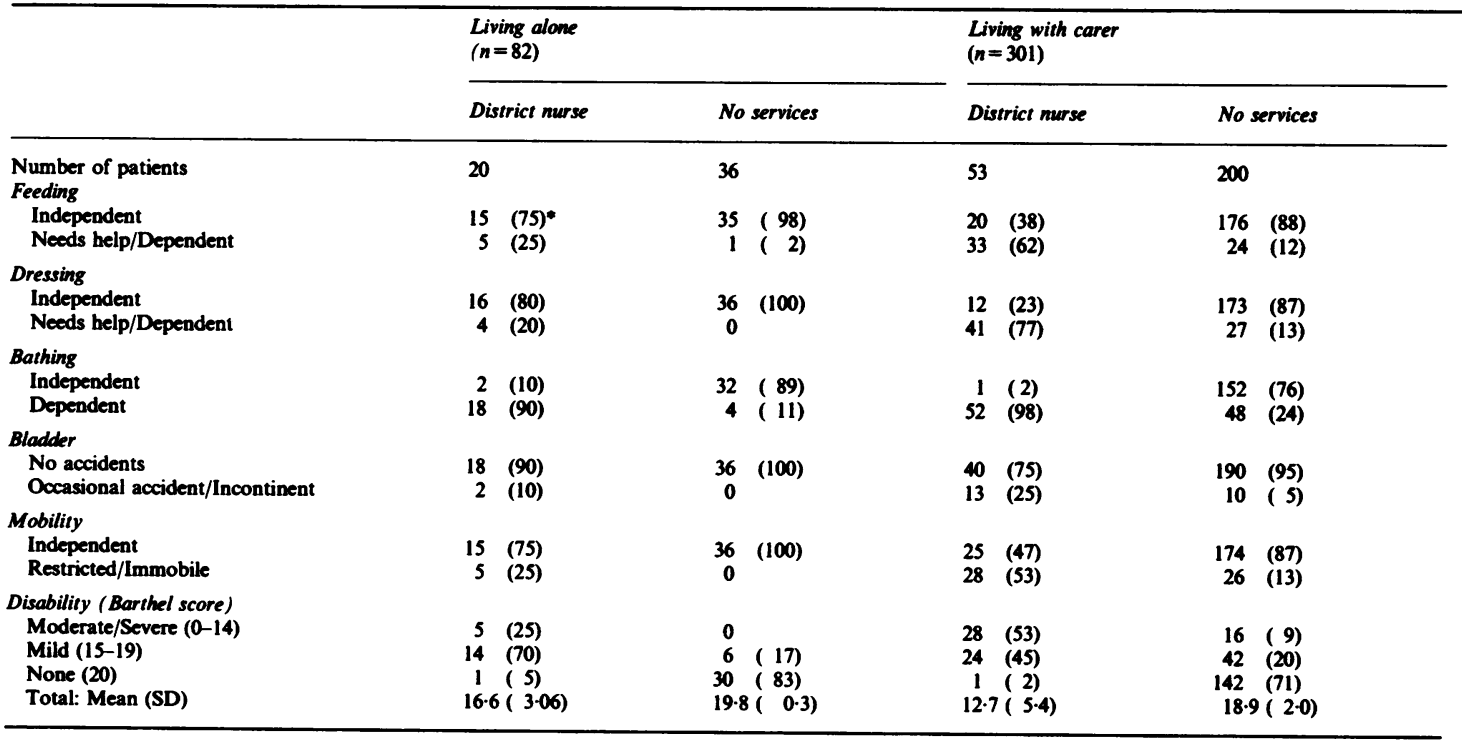

- Percentages in parentheses 
Table 5 Selected FAI activities for patients receiving/not receiving services

\begin{tabular}{|c|c|c|c|c|}
\hline & \multicolumn{2}{|l|}{ Living alone } & \multicolumn{2}{|c|}{ Living with carer } \\
\hline & Services & No services & Services & No services \\
\hline Number of patients & 46 & 36 & 101 & 200 \\
\hline $\begin{array}{l}\text { Cooking } \\
\text { Never } \\
\text { Occasionally } \\
\text { Most days }\end{array}$ & $\begin{array}{ll}14 & (30)^{*} \\
10 & (22) \\
22 & (48)\end{array}$ & $\begin{array}{rr}1 & (3) \\
1 & (3) \\
34 & (94)\end{array}$ & $\begin{array}{rr}80 & (80) \\
9 & (9) \\
12 & (11)\end{array}$ & $\begin{aligned} 116 & (58) \\
28 & (14) \\
56 & (28)\end{aligned}$ \\
\hline $\begin{array}{l}\text { Washing up } \\
\text { Never } \\
\text { Occasionally } \\
\text { Most days }\end{array}$ & $\begin{aligned} 8 & (17) \\
0 & \\
38 & (83)\end{aligned}$ & $\begin{array}{rr}1 & (3) \\
0 & \\
35 & (97)\end{array}$ & $\begin{array}{ll}65 & (64) \\
11 & (11) \\
25 & (25)\end{array}$ & $\begin{array}{rr}55 & (27) \\
18 & (9) \\
127 & (64)\end{array}$ \\
\hline $\begin{array}{l}\text { Washing clothes } \\
\text { Never } \\
\text { Occasionally } \\
\text { Most weeks }\end{array}$ & $\begin{array}{rr}30 & (65) \\
3 & (7) \\
13 & (28)\end{array}$ & $\begin{array}{rr}4 & (11) \\
2 & (6) \\
30 & (83)\end{array}$ & $\begin{aligned} 86 & (85) \\
0 & \\
15 & (15)\end{aligned}$ & $\begin{array}{rr}141 & (70) \\
10 & (5) \\
49 & (25)\end{array}$ \\
\hline $\begin{array}{l}\text { Heavy housework } \\
\text { Never } \\
\text { Occasionally } \\
\text { Most days }\end{array}$ & $\begin{array}{rr}40 & (87) \\
4 & (9) \\
2 & (4)\end{array}$ & $\begin{array}{rr}4 & (11) \\
1 & (3) \\
31 & (86)\end{array}$ & $\begin{aligned} 94 & (94) \\
1 & (1) \\
6 & (5)\end{aligned}$ & $\begin{aligned} 106 & (53) \\
21 & (10) \\
73 & (37)\end{aligned}$ \\
\hline $\begin{array}{l}\text { Shopping } \\
\text { Never } \\
\text { Occasionally } \\
\text { Most weeks }\end{array}$ & $\begin{aligned} 33 & (71) \\
3 & (7) \\
10 & (22)\end{aligned}$ & $\begin{array}{rr}8 & (22) \\
1 & (3) \\
27 & (75)\end{array}$ & $\begin{aligned} 93 & (92) \\
1 & (1) \\
7 & (7)\end{aligned}$ & $\begin{array}{ll}89 & (44) \\
20 & (10) \\
91 & (46)\end{array}$ \\
\hline Total score: Mean (SD) & $29.2(7.4)$ & $42.6(8.0)$ & $23.3(7.6)$ & $34.8(11.0)$ \\
\hline
\end{tabular}

* Percentages in parentheses

Health District are providing help to those patients who most need it. Thirty eight per cent of those living at home received some community-based assistance one year after their stroke. The most used resources were district nurses, home helps, meals on wheels, and attendance at a day centre. Nine per cent of surviving patients were in long-term residential care and most were moderately or severely disabled both mentally and physically.

Our figures suggest that each year, in an average health district of 250000 , the district nursing and home help services will be helping 37 patients who had suffered a stroke one year previously. Also, 27 patients in long-term residential care will be one year post stroke. These figures are not, however, those for the total number of stroke patients receiving services. They do not take into account either the length of time a patient is cared for (short or long term) or whether patients received any services before their stroke.

The sample studied should be representative of most health districts. Few patients admitted to hospital should have been missed, and we think most patients treated at home were registered. ${ }^{5}$ Eleven per cent of patients could not be followed up, but there is no reason to suppose that this was a source of bias as our information suggested that this group was similar in disability to the whole sample. The incidence recorded in our study is similar to that of other community studies. ${ }^{6}$

This study was concerned with relatively "objective" observations and has not directly attempted to ascertain the "need" for help accordin to the perceptions of the patient or the relativesconcerned. Some patients with no observable problem $c$ still expressed a need or desire for help which they were not getting. Further, the "stress" felt by carers is now. taken into account here. (This will be considered in $\&$ future paper.) With these limitations clearly understood, it seems that most patients left with a mild or moderate/severe disability and living alone are receiving help.

In addition, this study suggests that few, if any, of the patients in long-term residential care could be managed at home. Only 14 of these had "normal" mental function, as assessed by the Hodkinson tests, and all of these were significantly disabled. It seems, therefore, that those who can get home do so.

Detailed analysis of the permutations and combinations of services has not been conducted, but it is interesting how few patients (12) received all three of the main visiting services. This may reflect specific tailoring of services to a patient's needs; alternatively, it is possible that support is accepted by the patient for its human contact rather than its specific content. Three other observations are of interest. Firstly, there was a strong association between needing help with bathing and seeing the district nurse. Secondly, meals on wheels were rarely received every day. While it is possible that patients cooked for themselves, it seems more likely that other people provided food on the days not catered for. Thirdly, it seems that many patients $(44 \%)$ had seen their GP within the preceding 
month, suggesting that some medical after-care was continuing.

In conclusion, this study shows that in our health district those patients needing some personal or domestic help were receiving visits from one or more of the services. Relatively few patients with physical dependency relied solely on their carers, but the burden placed on carers may still be considerable. Further, providing more community support is unlikely to increase the number able to live at home, and we have little evidence to suggest that resources are being wasted on patients not needing help.

We are grateful to the Chest, Heart, and Stroke Association for financial help to Mrs J Legh-Smith, to the Department of Health and Social Security for their continuing financial support, to all the doctors, nurses, and others who have cooperated fully in this research, to the patients and their families for their forbearance in answering our questions, and to Ms S Burke for useful comments.

\section{References}

${ }^{1}$ Skilbeck CE, Wade DT, Langton Hewer R, Wood, VA. Recovery after stroke. J Neurol Neurosurg Psychiatry 1983; 46: 5-8.

${ }^{2}$ Garraway WM, Walton MS, Akhtar AJ, Prescott RJ. The use of health and social services in the management of stroke in the community: results from a controlled trial. Age \& Ageing 1981; 10: 95-104.

3 Jones DA, Vetter NJ. Formal and informal support received by carers of elderly dependents. $\mathrm{Br}$ Med J 1985; 291: 643-5.

${ }^{4}$ Opit LJ. Domiciliary care for the elderly sick-economy or neglect? Br Med J 1977; 1: 30-3.

${ }^{5}$ Wade DT, Langton-Hewer R, Skilbeck CE, Bainton D, Burns-Cox C. Controlled trial of a home-care service for acute stroke patients. Lancet 1985; 1: 323-6.

${ }^{6}$ Aho K, Harmsen P, Hatano S, Marquardsen J, Smirnov VE, Strasser T. Cerebrovascular disease in the community: Results of a WHO collaborative Study. Bull WHO 1980; 58: 113-30.

${ }^{7}$ Granger CV, Dewis LS, Peters NC, Sherwood CC. Stroke rehabilitation: Analysis of repeated Barthel index measures. Arch Phys Med \& Rehab 1979; 60: 14-7.

${ }^{8}$ Holbrook M, Skilbeck CE. An activities index for use with stroke patients. Age \& Ageing 1983; 12: 166-70.

${ }^{9}$ Hodkinson HM. Evaluation of a mental test score for assessment of mental impairment in the elderly. Age \& Ageing 1972; 1: 233-8. 